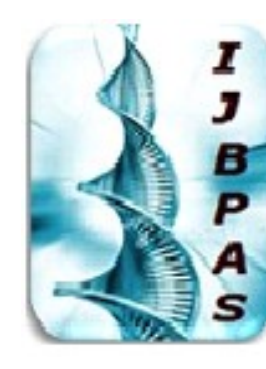

International Journal of Biology, Pharmacy and Allied Sciences (IJBPAS)

'A Bridgs Betusen Caboratory and QRendor'

WWW.ijbpas.com

\title{
DETERMINATION OF ANTIPSYCHOTIC MEDICATIONS IN HUMAN PLASMA BY UPLC: PHARMACOKINETIC STUDY
}

\section{SHARATH BABU BOOTAM ${ }^{*}$ AND SRIDHAR BABU GUMMADI ${ }^{2}$}

1: Research scholar, Mewar University, Gangrar, Chittorgarh, Rajasthan

2: Research Supervisor, Mewar University, Gangrar, Chittorgarh, Rajasthan

*Corresponding Author: E Mail: sharath.bootham@gmail.com

Received $19^{\text {th }}$ May 2021; Revised $4^{\text {th }}$ June 2021; Accepted $9^{\text {th }}$ July 2021; Available online $25^{\text {th }}$ Sept. 2021

https://doi.org/10.31032/IJBPAS/2021/10.9.1010

\section{ABSTRACT}

A simple and sensitive ultra-performance liquid chromatography (UPLC) method has been developed and validated for simultaneous estimation of olanzapine (OLZ), risperidone (RIS) and 9-hydroxyrisperidone (9-OHRIS) in human plasma in vitro. The sample preparation was performed by simple liquid-liquid extraction technique. The analytes were chromatographed on a Waters Acquity H class UPLC system using isocratic mobile phase conditions at a flow rate of $0.3 \mathrm{~mL} / \mathrm{min}$ and Acquity UPLC BEH shield RP18 column maintained at $40^{\circ} \mathrm{C}$. Quantification was performed on a photodiode array detector set at $277 \mathrm{~nm}$ and clozapine was used as internal standard (IS). OLZ, RIS, 9-OHRIS and IS retention times were found to be $0.9,1.4, .1 .8$ and $3.1 \mathrm{~min}$, respectively, and the total run time was $4 \mathrm{~min}$. The method was validated for selectivity, specificity, recovery, linearity, accuracy, precision and sample stability. The calibration curve was linear over the concentration range $1-100 \mathrm{ng} / \mathrm{mL}$ for OLZ, RIS and 9-OHRIS. Intra- and inter-day precisions for OLZ, RIS and 9-OHRIS were found to be good with the coefficient of variation $<6.96 \%$, and the accuracy ranging from 97.55 to $105.41 \%$, in human plasma. The validated UPLC method was successfully applied to the pharmacokinetic study of RIS and 9-OHRIS in human plasma.

Keywords: UPLC; risperidone; 9-hydroxyrisperidone; olanzapine; pharmacokinetics 


\section{INTRODUCTION}

Schizophrenia is a common chronic neuropsychiatric illness affecting patients worldwide. This condition requires the initiation of treatment with antipsychotic medications, of which second- generation drugs [risperidone (RIS) and olanzapine (OLZ)] are the most commonly prescribed in patients. Second-generation antipsychotic drugs exhibit beneficial effects on anxiety, depression and mania, and exert reduced extra-pyramidal side effects (Leucht et al., 2009; Ansari and Mulla, 2014; Lieberman et al., 2005). Both risperidone and olanzapine are widely prescribed second generation antipsychotic drugs, and olanzapine is often coadministered with risperidone [1]. 9Hydroxyrisperidone (9-OHRIS) is the major metabolite of RIS, formed in-vivo through hepatic oxidation, and itself is biologically active. Correlation of its plasma levels, parent drug levels and clinical effects is complicated (Sheehan et al., 2010). Of the numerous metabolic enzymes, the cytochrome P450 family account for the metabolism of the majority of psychotropic medications. Cytochrome P450 has a variable expression pattern and these microsomal enzymes are subjected to genetic, pharmacogenetic and epigenetic

variations, which leads to pharmacokinetic variations and results in unexpected alterations and clinical response [2]. Quantification of antipsychotic medications in human biological matrices requires high precision and greater sensitivity since most of these compounds are present in low concentrations in plasma.

Moreover, as most of the antipsychotic medications are prescribed along with other drugs in schizophrenia patients, drug interactions can be expected.

In the past, various high-performance liquid chromatography (HPLC) methods with UV detection [3], coulometric [4] and fluorescence detection [4] have been reported to detect and quantify antipsychotic medications. Recently, several studies have utilized methods based on liquid chromatography coupled with mass spectrometry (LC-MS/MS) to increase sensitivity in detection with shorter run times [5]. Although LCMS/MS methods are advantageous in many ways, the expensive instrumentation and de-creased accessibility to routine hospital practice and laboratories are their major limitations.

Considering these facts, an ultrahigh 
performance liquid chromatography (UPLC) with diode array detection (DAD) for OLZ, RIS and 9-OHRIS was developed and validated. Further, the method was designed using a simple mobile phase in isocratic conditions, devoid of strong buffers and ion pairing agents to achieve better reproducibility with less interference. The method has a shorter run time, and can even be transferred to LCMS/MS if needed as compatible buffer and chromatographic conditions were used. The proposed method was successfully applied to a pharmacokinetic study of risperidone in human volunteers. The developed method can also be utilized for therapeutic drug monitoring of OLZ, RIS and 9-OHRIS.

\section{MATERIALS AND METHODS}

\section{Chemicals and reagents}

Acetonitrile, methanol and ammonium acetate of HPLC grade were purchased from Sigma-Aldrich, India. The reference standards of RIS, 9-OHRIS, OLZ and clozapine (IS) were purchased from Sigma- Aldrich, India. Methyl tert-butyl ether and acetic acid of HPLC grade were obtained from HI media, India. Ammonia solution (25\% pure) was purchased from Merck, India. Blank human plasma was obtained from blood bank services XYZ
Hospitals, Hyderabad. Ultrapure water $(18.2 \mathrm{M} \Omega \mathrm{cm})$ was obtained from a MilliQ water purification system from Millipore (Milford, USA).

\section{Instrumentation and chromatography conditions}

The UPLC instrument consisted of a Waters Acquity $\mathrm{H}$ class UPLC system equipped with a quaternary pump and 96vial autosampler coupled with a diode array UV detector (Waters, Milford, MA, USA). The chromatographic separation was performed on an Acquity UPLC BEH C18 column from Waters $(2.1 \times 100 \mathrm{~mm}$; $1.7 \mu \mathrm{m})$. The column temperature was set at $40^{\circ} \mathrm{C}$ and the autosampler was kept at $10^{\circ} \mathrm{C}$. The mobile phase composed of a mixture of $10 \mathrm{mM}$ ammonium acetate buffer at a $\mathrm{pH}$ of 3.5, which was adjusted with acetic acid $(70 \%, \mathrm{v} / \mathrm{v})$ and acetonitrile $(30 \%, v / v)$ at a flow rate of $0.3 \mathrm{~mL} / \mathrm{min}$. Before analysis, the mobile phase was filtered through a $0.22 \mu \mathrm{m}$ membrane filter and degassed by ultra-sonication. A $5 \mu \mathrm{L}$ injection of each sample was loaded on to the system and total analysis time was 4 min. DAD was set at $277 \mathrm{~nm}$. The sampling needle was washed with $400 \mu \mathrm{L}$ of strong wash (ACN-water, 65:35) to reduce carry-over and $400 \mu \mathrm{L}$ of weak wash (ACN-water, 30/70). Data 
acquisition was done using Empower 3 software version 1.0 (Waters).

Preparation of stock and working standard solution

OLZ, RIS and 9-OHRIS stock solutions of $1 \mathrm{mg} / \mathrm{mL}$ were prepared by dissolving suitable amounts of the single drugs in methanol. Mixtures of stock solutions OLZ, RIS and 9-OHRIS (100 $\mu \mathrm{g} / \mathrm{mL})$ were prepared in methanol. Clozapine was selected as IS based on a previous study (Idris and Elgorashe, 2013). Further, clozapine has been used widely only in treatment-resistant schizophrenia (Meyer, 2011). Therefore we selected clozapine as IS. The IS stock solution of $200 \mu \mathrm{g} / \mathrm{mL}$ was prepared in methanol. The stock solution of OLZ, RIS, 9-OHRIS and IS were stable at $4^{\circ} \mathrm{C}$ for 1 month. Further dilution was made in methanol-water $(50: 50, \mathrm{v} / \mathrm{v})$ to produce working stock solutions for the calibration standards and quality control (QC) standards. The IS working solution $(5 \mu \mathrm{g} / \mathrm{mL})$ was prepared in methanol-water $(50: 50 \mathrm{v} / \mathrm{v})$. Calibration curve samples were prepared by spiking $240 \mu \mathrm{L}$ of human blank plasma with the appropriate mixture of working solutions of OLZ, RIS and 9-OHRIS $(10 \mu \mathrm{L})$ on the day of analysis. All the samples were stored together at $80 \pm 10^{\circ} \mathrm{C}$ until analysis.

\section{Sample preparation}

Sample preparation was carried out by the liquid-liquid extraction procedure. To a $250 \mu \mathrm{L}$ of aliquot of plasma, $25 \mu \mathrm{L}$ of IS working solution and $250 \mu \mathrm{L}$ of $10 \mathrm{mM}$ ammonium acetate $(\mathrm{pH}$ 9.0) were added and mixed for $20 \mathrm{~s}$ on a spinix vortex shaker (Tarsons, India). The mixture was vortexed for $30 \mathrm{~s}$. A $3.0 \mathrm{~mL}$ aliquot of tertbutylmethylether was added and vortex mixed for $5 \mathrm{~min}$, and then centrifuged at $10,000 \mathrm{rpm}$ for $5 \mathrm{~min}$ at $4^{\circ} \mathrm{C}$ on an Eppendorf 5810R centrifuge (Eppendorf AG, Hamburg, Germany). The clear supernatant organic layer $(2.5 \mathrm{~mL})$ was transferred into $5 \mathrm{~mL}$ polypropylene tubes and evaporated to dryness at $40^{\circ} \mathrm{C}$ using a nitrogen evaporator (Turebovap $\AA$, Biotage, USA). The residue was reconstituted in $200 \mu \mathrm{L}$ of the mobile phase, vortex mixed for $1.0 \mathrm{~min}$ and centrifuged at 10,000rpm for $5 \mathrm{~min}$. Finally, $190 \mu \mathrm{L}$ of the clear supernatant was transferred into a glass micro-vial and $5 \mu \mathrm{L}$ was injected onto the UPLC system for analysis.

\section{Method validation}

The method was validated for selectivity, specificity, recovery, linearity, accuracy, precision and stability using US Food and Drug Ad-ministration guidelines (US DHHS et al., 2001) for assay in human 
plasma.

\section{Carry-over and limit of quantification}

Carry-over effect was assessed by injecting the highest calibration standard just before the blank plasma. The lower limit of quantitation (LLOQ) was defined as the first point of the calibration standard with lowest concentration (signal-to-noise ratio $\geq 10: 1$ ) that can be calculated with an acceptable precision and accuracy.

\section{Selectivity and specificity}

Selectivity of the method was assessed by analysing six different donor's human blank plasma injected at the beginning of the validation and investigating the potential interferences at the LC peak region for analytes and IS. At least five out of six lots should have responses less than five times the LLOQ level response in the same matrix.

\section{Recovery}

The recoveries of OLZ, RIS and 9-OHRIS were assessed by the analyses of the three concentrations $(5,45$ and $80 \mathrm{ng} / \mathrm{mL})$ whereas the recovery of IS was determined at a single concentration of $5 \mu \mathrm{g} / \mathrm{mL}$. Recovery was calculated as the extracted spiked plasma peak area response compared with the response obtained for neat standard solution at equivalent concentrations by the liquid-liquid extraction process. The analyte responses from the extracted samples at known concentrations were compared with responses of un-extracted standards.

\section{Linearity}

Linearity was evaluated by linear regression analysis with the use of working standard solutions and spiked plasma samples containing the drugs of interest at different concentrations within the range 1-100 ng/mL for all analytes. The calibration curves were constructed by plotting the ratio of the peak area of each analyte to the peak area of internal standard vs the nominal drug concentration. The slopes and intercept were calculated with least square linear regression analysis of the data with the use of a $1 / x 2$ (where $x$ is the concentration) weighting factor. The acceptance criterion for each back-calculated standard concentration was $\pm 15 \%$ deviation from the nominal value except at LLOQ, which was set as $\pm 20 \%$ (US DHHS et al., 2001).

\section{Accuracy and precision}

The validation method evaluation of the accuracy and precision in the experiments were performed for four independent series (including ruggedness) in plasma. The intra- and inter-day assay accuracy and precision were estimated by analyzing six 
replicates containing analytes at three different QC levels, that is, 1, 5, 45 and 80 $\mathrm{ng} / \mathrm{mL}$. Accuracy represents the closeness of agreement between the mean values obtained from the series of measurements by the method and the actual value. The accuracy should be within $85-115 \%$ of the nominal value, except at LLOQ, where it should not deviate by no more than $20 \%$ (US DHHS et al., 2001). Precision, which represents the closeness of agreement among a series of measurements obtained from multiple sampling, was estimated with variances of repeatability (intra-day variances) and intermediate precision (sum of intra-day and inter-day variances). The precision should not exceed $\pm 15 \%$ relative standard deviation (RSD), except for the LLOQ, where it should be within $\pm 20 \%$ of RSD (US DHHS et al., 2001).

\section{Stability}

Stability tests were performed to evaluate the stability of analytes in plasma samples under different conditions. The bench-top stability study assessed the stability of analytes in plasma at room temperature for $8 \mathrm{~h}$, whereas a post-preparative stability study assessed the stability of analytes in the treated samples (autosampler stability for $26 \mathrm{~h}$ at $\left.10^{\circ} \mathrm{C}\right)$. These were determined at low $(5 \mathrm{ng} / \mathrm{mL})$ and high $(80 \mathrm{ng} / \mathrm{mL}) \mathrm{QC}$ concentrations. The freeze-thaw stability was determined after three freeze and thaw cycles and long-term stability was determined by accessing QC samples stored at $80^{\circ} \mathrm{C}$ for 30 days.

\section{Pharmacokinetic study}

Twenty healthy male volunteers aged between 24 and 31 years $(26.8 \pm 2.4$ years $)$ and weighing from 62 to $82 \mathrm{~kg}(70.7 \pm 6.8$ $\mathrm{kg}$ ) were enrolled in the study and informed consent was obtained. The study was approved by the Institutional Human Ethics Committee prior to commencing and was performed in accordance with the principles of the World Medical Association's Declaration of Helsinki. The volunteers underwent screening examinations that included a medical history and physical examination. Volunteers received a single $2 \mathrm{mg}$ risperidone tablet (Respidon-2, Torrent Pharmaceuticals Ltd, India) along with 200 $\mathrm{mL}$ water. Serial venous blood samples (2 $\mathrm{mL}$ ) for the determination of plasma RIS and 9-OHRIS concentrations were obtained from forearm vein before dosing and at 0.5 , 1.0, 2.0, 4.0, 8.0, 12.0 and $24 \mathrm{~h}$ after dosing. Samples were collected in K2.EDTA tube and plasma was separated by centrifugation at $4000 \mathrm{rpm}$ and stored at $80^{\circ} \mathrm{C}$ until analysis. WinNonlin software 
5.1 was used to calculate the pharmacokinetics parameters using a noncompartmental model (Pharsight Corporation, Mountain View, CA, USA). Pharmacokinetic parameters including Cmax (maximum plasma concentration), Tmax (the time to reach Cmax), the area under the plasma concentration-time curve from time zero to last measurable time point $(A U C 0-t)$, the area under the plasma concentration-time curve from zero to

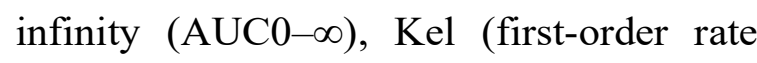
constant associated with the terminal (loglinear) portion of the curve) and T1/2 (the terminal half-life) were calculated.

\section{RESULTS AND DISCUSSION}

Optimization of the chromatographic conditions

A reverse-phase liquid chromatographic method was developed for the determination of OLZ, RIS and 9-OHRIS in human plasma samples using diode array detection. LC method development was carried out focusing on achieving sufficient resolution of target drugs and endogenous interferences in matrix within a short run time, with simple buffers. For this purpose, different mobile phases comprising several combinations of buffers (e.g. phosphate buffer and ammonium acetate buffer) and organic solvents (acetonitrile and methanol) along with altered flow rates (range of $0.200-0.500$ $\mathrm{mL} / \mathrm{min}$ ) were tested to optimize for an effective chromatographic resolution of OLZ, RIS, 9-OHRIS and IS. Using methanol in mobile phase produced broad peaks without symmetry and a long analysis time. When acetonitrile used as organic solvent in the mobile phase, the analysis time was reduced and peaks were more symmetrical and sharp. The best resolution of peaks achieved with isocratic mobile phase consisted of a mixture of acetonitrile-10 $\mathrm{mM}$ ammonium acetate (30:70; v/v) containing acetic acid with the $\mathrm{pH}$ adjusted to 3.5 at a flow rate of 0.3 $\mathrm{mL} / \mathrm{min}$ on an Acquity UPLC BEH C18 column. The utilization of a volatile buffer like ammonium acetate in mobile phase gives better column life and can be compatible with mass spectrometry, unlike phosphate buffers.

\section{Carry-over and limit of quantification}

No carry-over was observed when the highest calibration standard was analyzed just before the blank plasma. This indicated that a flow through needle configuration of the injector and a washing step of the column at the end of the chromatography separation were adequate to remove potential residues of the 
analytes. The LLOQ on the calibration curve was $1.0 \mathrm{ng} / \mathrm{mL}$ for all of the compounds and the signal-to-noise ratio in plasma was $\geq 10$.

\section{Selectivity and specificity}

Selectivity was evaluated by comparing the chromatograms of blank plasma, blank plasma spiked with IS and with analytes (1 $\mathrm{ng} / \mathrm{mL}$ ) and IS, and a kinetic study sample obtained $2 \mathrm{~h}$ after oral administration (2 $\mathrm{mg}$ risperidone tablet). As shown in Figure 1, no interfering peaks from endogenous compounds were observed at the retention times of analytes and IS. The total chromato-graphic run time was $4 \mathrm{~min}$. Figure 1. Representative UPLC chromatograms of olanzapine (OLZ), risperidone (RIS), 9- hydroxyrisperidone (9-OHRIS) and IS in human plasma.(a) Blank plasma sample; (b) blank plasma sample spiked with IS; (c) blank plasma spiked with analytes $(1 \mathrm{ng} / \mathrm{mL})$ and IS; and (d) pharmacokinetic plasma samples collected from healthy volunteers at $2.0 \mathrm{~h}$ time point following oral administration of RIS along with IS.

\section{Recovery}

Liquid-liquid extraction technique gave adequate recovery and cleaner samples. The results of the evaluation of neat standards vs plasma extracted standards were estimated for OLZ, RIS and 9-OHRIS (5, 45 and $80 \mathrm{ng} / \mathrm{mL}$ ) and the mean recoveries were $89.42 \pm 2.89,90.16 \pm 2.06$ and $90.13 \pm 1.82 \%$, respectively. The recovery of IS at $5 \mu \mathrm{g} / \mathrm{mL}$ was $84.25 \pm$ $3.23 \%$.

\section{Linearity}

The calibration curves exhibited excellent linearity with regression correlation coefficient ( $\mathrm{r} 2>0.998)$ over the concentration range of $1.0-100 \mathrm{ng} / \mathrm{mL}$ for all of the drugs in human plasma. The standard calibration curve had a consistent reproducibility over the standard concentrations across the calibration range. A typical regression equation was prepared by determining the best fit of peakarea ratio (peak area analyte/peak area IS) vs concentration, and fitted to $\mathrm{y}=\mathrm{mx}+\mathrm{c}$ using a weighting factor $(1 / \mathrm{x} 2)$. The lowest concentration with RSD $<20 \%$ was taken as the LLOQ and was found to be 1.0 $\mathrm{ng} / \mathrm{mL}$ for all the drugs. The percentage accuracies observed for the mean of backcalculated concentration for four calibration curves for the entire drugs were within 96.10-102.50. 


\begin{tabular}{|c|c|c|c|c|c|c|}
\hline \multicolumn{7}{|c|}{$\begin{array}{l}\text { Table 1. Intra- and inter-day precision and accuracy of olanzapine (OLZ), risperidone (IRS) and 9-hydroxyrisperidone (9-OHRSS) in hu- } \\
\text { man plasma in vitro }\end{array}$} \\
\hline \multirow{2}{*}{$\begin{array}{l}\text { Nominal } \\
\text { concentration } \\
\text { (ng/mL) }\end{array}$} & \multicolumn{3}{|c|}{ Intra-day $(n=6)$} & \multicolumn{3}{|c|}{ Inter-day $(n=18)$} \\
\hline & $\begin{array}{l}\text { Measured concentration } \\
\text { (mean } \pm S D \text {, ng/mL) }\end{array}$ & $C V(\%)$ & Accuracy $(\%)$ & $\begin{array}{l}\text { Measured concentration } \\
\text { (mean } \pm S D, n g / m L)\end{array}$ & $\operatorname{CV}(\%)$ & Accuracy $(\%)$ \\
\hline \multicolumn{7}{|l|}{ RIS } \\
\hline 1.12 & $1.13 \pm 0.06$ & 5.31 & 100.89 & $1.15 \pm 0.08$ & 6.96 & 102.68 \\
\hline 5.12 & $5.18 \pm 0.13$ & 2.51 & 101.17 & $5.28 \pm 0.36$ & 6.82 & 103.13 \\
\hline 45.82 & $46.88 \pm 0.72$ & 1.54 & 102.31 & $48,30 \pm 2.20$ & 4.55 & 105.41 \\
\hline 80.78 & $80.61 \pm 1.62$ & 2.01 & 99.79 & $80.12 \pm 3.29$ & 4.11 & 99.18 \\
\hline \multicolumn{7}{|l|}{ 9-OHARS } \\
\hline 1.09 & $1.07 \pm 0.04$ & 3.74 & 98.17 & $1.14 \pm 0.07$ & 6.14 & 104.59 \\
\hline 5.10 & $5.06 \pm 0.13$ & 2.57 & 99.22 & $5.18 \pm 0.31$ & 5.98 & 101.57 \\
\hline 45.21 & $46.72 \pm 0.80$ & 1.71 & 103.34 & $45.68 \pm 2.34$ & 5.12 & 101.04 \\
\hline 81.48 & $80.49 \pm 0.74$ & 0.92 & 98.78 & $84.15 \pm 3.44$ & 4.09 & 103.28 \\
\hline \multicolumn{7}{|l|}{ OlZ } \\
\hline 1.21 & $1.20 \pm 0.02$ & 1.67 & 99.17 & $1.26 \pm 0.07$ & 5.56 & 104.13 \\
\hline 4.98 & $5.15 \pm 0.16$ & 3.11 & 103.41 & $4.94 \pm 0.22$ & 4.45 & 99.20 \\
\hline 44.74 & $46.02 \pm 1.04$ & 2.26 & 102.86 & $45.35 \pm 1.94$ & 4.28 & 101,36 \\
\hline 81,32 & $79,33 \pm 1,65$ & 2.08 & 97,55 & $81.27 \pm 2.92$ & 3.59 & 99.94 \\
\hline
\end{tabular}




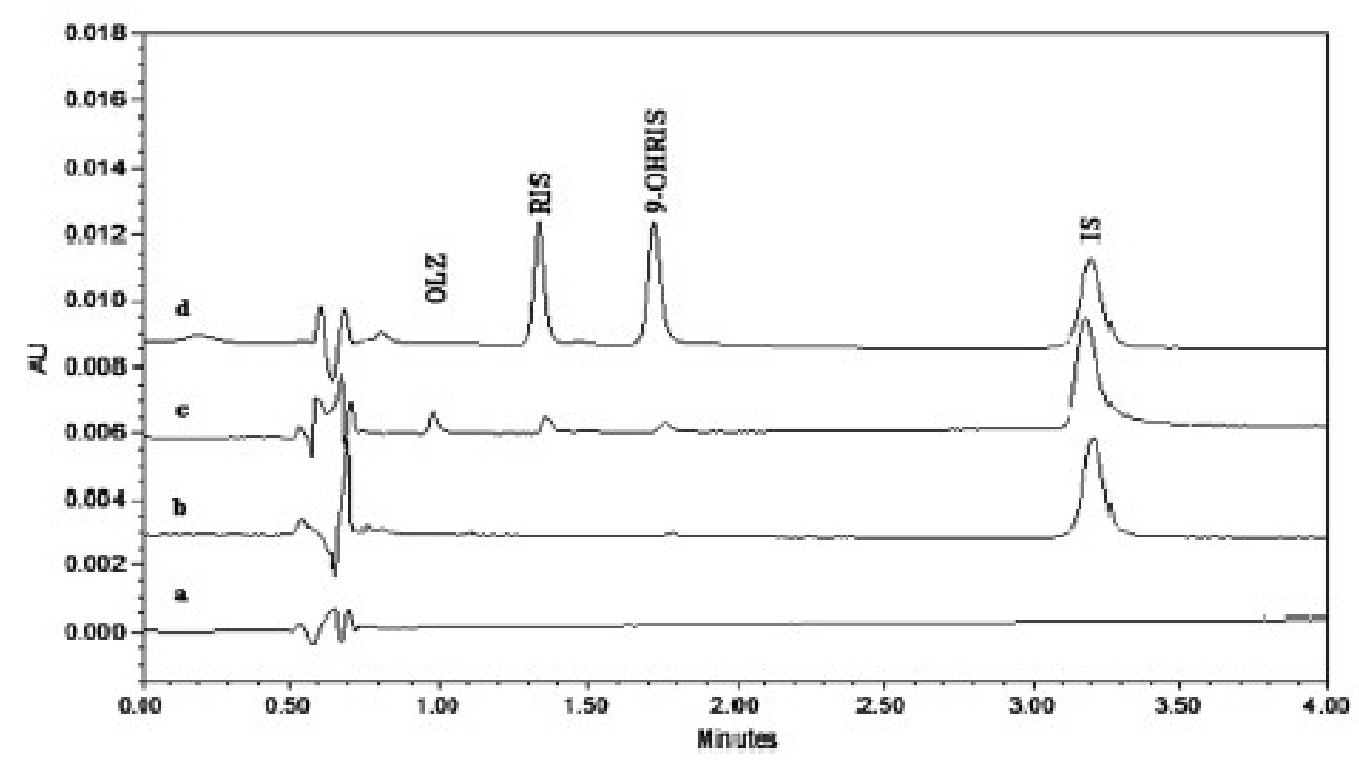

Figure 1. Representative UPLC chromatograms of olanzapine (OLZ), risperidone (RIS), 9-hydroxyrisperidone (9-OHRIS) and IS in human plasma. (a) Blank plasma sample; (b) blank plasma sample spiked with IS; (c) blank

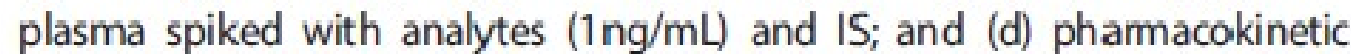
plasma samples collected from healthy volunteers at $2.0 \mathrm{~h}$ time point following oral administration of RIS along with IS.

\begin{tabular}{|c|c|c|c|c|c|c|c|c|}
\hline \multicolumn{9}{|c|}{ Table2. Stability of RS, 9.OHRIS and OLZZ in human plasma in vitro under different conditions ( $n=6$ ) } \\
\hline \multirow{2}{*}{$\begin{array}{l}\text { Nominal } \\
\text { concentration } \\
\text { (ng/mLl) }\end{array}$} & \multicolumn{2}{|c|}{$\begin{array}{c}\text { Bench-top } \\
\text { (room temperature for } 8 \mathrm{hi} \text { ) }\end{array}$} & \multicolumn{2}{|c|}{$\begin{array}{l}\text { Autossmpler } \\
\text { (8'Cfor 26h) }\end{array}$} & \multicolumn{2}{|c|}{ Freeze-thaw cycles } & \multicolumn{2}{|c|}{$\begin{array}{l}\text { Long-tem stability } \\
\left(-80^{\circ} \mathrm{C} \text { for } 30 \text { days) }\right.\end{array}$} \\
\hline & $\begin{array}{l}\text { Neasurued concentration } \\
\text { (mean } \$ 50, \text { nglmL) }\end{array}$ & Bias $1 \%(\%)$ & $\begin{array}{c}\text { Measured } \\
\text { concentration } \\
\text { (mean } \pm S D, \text { ng/mL) }\end{array}$ & Bias (\%) & $\begin{array}{c}\text { Measurued } \\
\text { concentration } \\
\text { (mean } \pm S D, \text { ng/mll) }\end{array}$ & Bias $(\%)$ & $\begin{array}{c}\text { Measurued } \\
\text { concentration } \\
\text { (mean } \$ \text { SD ng/mLL) }\end{array}$ & Bias 19 \\
\hline \multicolumn{9}{|l|}{ RS } \\
\hline 5.12 & $4.97 \pm 0.10$ & -2.93 & $5.19 \pm 0.05$ & 137 & $4.91 \pm 0.08$ & -4.10 & $5.25 \pm 0.08$ & 2.5 \\
\hline $\begin{array}{l}\text { 80.78 } \\
\text { 9.0HRS }\end{array}$ & $79.83 \pm 1.03$ & -1.18 & $81.97 \pm 1.32$ & 147 & $79.91 \pm 0.95$ & -1.08 & $82.57 \pm 1.07$ & 2.2 \\
\hline 5.10 & $5.25 \pm 0.14$ & 2.94 & $5.04 \pm 0.21$ & -1.18 & $5.23 \pm 0.30$ & 2.55 & $4.99 \pm 0.23$ & -2.11 \\
\hline B1.48 & $82.12 \pm 2.51$ & 0.79 & $79.73 \pm 2.15$ & -2.15 & $80.04 \pm 0.72$ & -1.77 & $82.41 \pm 2.18$ & 1.14 \\
\hline al & & & & & & & & \\
\hline 4.98 & $4.93 \pm 0.17$ & -1.00 & $5.07 \pm 0.19$ & 1.81 & $5.03 \pm 0.16$ & 1.00 & $5.02 \pm 0.26$ & 0.81 \\
\hline 8132 & $79.87 \pm 1.95$ & -1.78 & $79.04 \pm 2.25$ & -2.80 & $80.04 \pm 0.72$ & -1.57 & $78.91 \pm 1.95$ & -2.91 \\
\hline
\end{tabular}




\section{Accuracy and precision}

The accuracy and precision of the method were evaluated as intra-day (repeatability) and inter-day (intermediate) human plasma for entire drug samples and are summarized in Table 1. The intra- and inter-day precisions were $<6.96 \%$ and the accuracy ranged from 97.55 to 105.41 at all levels. All the values were within the accepted range and the method was accurate and precise.

\section{Stability}

The stability of OLZ, RIS, and 9-OHRIS in human plasma were investigated under a variety of storage and process conditions: in plasma at room temperature for $8 \mathrm{~h}$; in the autosampler for $26 \mathrm{~h}$ at $10^{\circ} \mathrm{C}$; after three freeze-thaw cycles; and after long-term storage at $80^{\circ} \mathrm{C}$ for 30 days. Results are summarized in Table 2 and indicated that the samples of OLZ, RIS and 9OHRIS were stable under the conditions described.

\section{Applicability of the validated method}

We successfully validated the novel method of quantification of analytes, viz. RIS and 9-OHRIS, after a single oral dosing of $2 \mathrm{mg}$ RIS (Respidon-2, Torrent Pharmaceuticals Ltd, India) tablets in healthy volunteers. The maximum concentration of RIS in our study was almost twice that of its major metabolite measured in our assay method, viz. 9-OHRIS, both compounds being quantified up to $24 \mathrm{~h}$ after a single oral dosing of RIS $(16.48 \pm 5.07$ vs $10.33 \pm 1.90 \mathrm{ng} / \mathrm{mL}$ ). On similar lines of reference, the time taken to attain this maximum concentration in plasma for RIS was nearly one-quarter that for 9OHRIS $(0.80 \pm 0.25$ vs $4.0 \pm 1.12 \mathrm{~h})$. The AUCs of RIS from 0 to $12 \mathrm{~h}$ and 0 to $\infty \mathrm{h}$ were $92.64 \pm 27.79$ and103.93 \pm 32.38 (ng $\mathrm{h} / \mathrm{mL}$ ), which were less than the corresponding values for its metabolite (141. $80 \pm 32.41$ and 191.80 $\pm 49.81 \mathrm{ng} \mathrm{h} / \mathrm{mL}$, respectively). Moreover, the corresponding plasma half-lives for the parent and its major metabolite were $6.17 \pm 1.76$ and $11.54 \pm$ $3.11 \mathrm{~h}$, respectively. Finally, the firstorder elimination rate constants associated with the terminal part of plasma concentration-time curves were $0.12 \pm 0.04$ and $0.06 \pm 0.02 / \mathrm{h}$, respectively. Additionally, we calculated the apparent volumes of distribution and clearance of the parent to be $2.49 \pm 0.53$ $\mathrm{L} / \mathrm{kg}$ and $4.95 \pm 1.36 \mathrm{~mL} / \mathrm{min} \mathrm{kg}$, respectively. The corresponding values 
for the active metabolite of RIS in the participants were $2.56 \pm 0.60 \mathrm{~L} / \mathrm{kg}$ and $2.67 \pm 0.79 \mathrm{~mL} / \mathrm{min} \mathrm{kg}$. The values reported for these pharmacokinetic parameters were comparable to previously reported ones (Liu et al.,
2013). The profile of mean plasma concentration of RIS and 9-OHRIS vs time is shown in Figure 2.

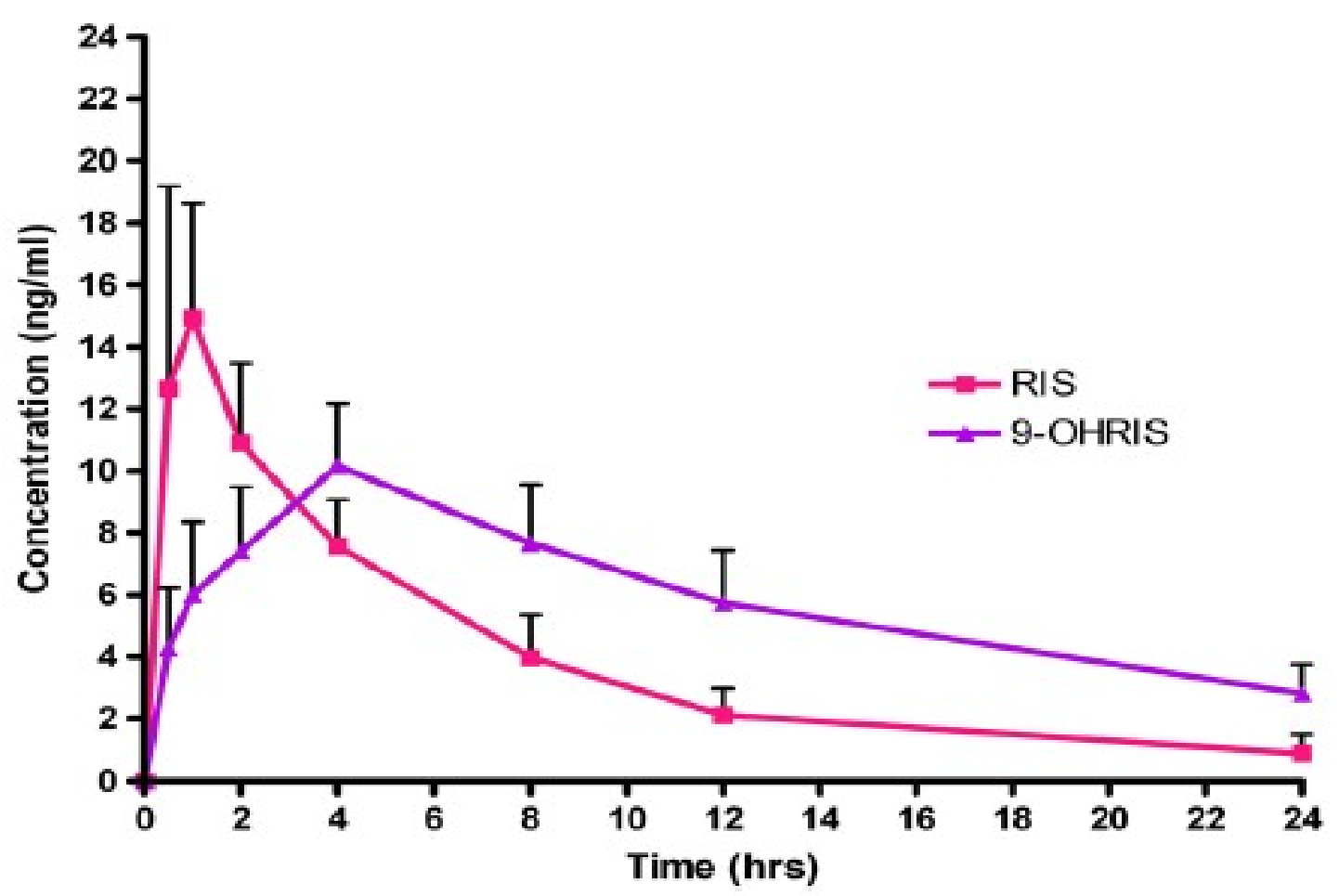

Figure 2. Mean plasma concentration-time profile of RIS and 9-OHRIS in human plasma after oral administration of $2 \mathrm{mg}$ of risperidone tablet. 


\section{CONCLUSION}

A simple, sensitive and reliable UPLC method has been developed and validated for simultaneous determination of OLZ, RIS and 9-OHRIS in human plasma in vitro. This UPLC method has significant advantages including good resolution between peaks and adequate extraction recovery with shorter chromatographic run time. The developed method was successfully adopted to evaluate the pharmacokinetic parameters of a second-generation antipsychotic drug, RIS, and its major metabolite, 9-OHRIS, in human plasma. It can be employed in therapeutic drug monitoring practices and clinical toxicological assays. This method has similar sensitivity to other methods developed using LC-MS/MS.

\section{REFERENCES}

[1] Ansermot N, Brawand-Amey M, Kottelat A and Eap CB. Fast quantification of ten psychotropic drugs and metabolites in human plasma by ultra- high performance liquid chromatography tandem mass spectrometry for therapeutic drug monitoring. Journal of

Chromatography A 2012; 1292: 160172. Ansari S and Mulla S. Analysis of variables affecting drug compliance in schizophrenia. Industrial Psychiatry Journal 2012; 23(1): 5860.

[2] Basile VS, Masellis M, Potkin SG and Kennedy JL. Pharmacogenomics in schizophrenia: the quest for individualized therapy. Human Molecular Genetics 2003; 11(20): 2517-2530.

[3] Crisafulli C, Fabbri C, Porcelli S, Drago A, Spina E, De Ronchi D and Serreti A. Pharmacogenetics of antidepressants. Frontiers in Pharmacology 2012; 2: 1-21.

[4] Dusci LJ, Peter Hackett L, Fellows LM and Ilett KF. Determination of olanzapine in plasma by highperformance liquid chromatography using ultraviolet absorbance detection. Journal of Chromatography B: Analytical Technologies in the Biochemical and Life Sciences 2003; 773(2): 191-197.

[5] Idris AM and Elgorashe RE. Sequential injection chromatography for separa- tion and quantification of chlorpromazine in human urine and pharma- ceutical formulations. Journal of AOAC International 2012; 96(2): 282-9.

[6] Jayaram MB, Hosalli $\mathrm{P}$ and Stroup TS. Risperidone versus olanzapine for schizophrenia. (Review.) The Cochrane. Library 2008; 2. 
[7] Kristoffersen L, Bugge A, Lundanes E and Slordal L. Simultaneous determi- nation of citalopram, fluoxetine, paroxetine and their metabolites in plasma and whole blood by high- performance liquid chromatography with ultraviolet and fluorescence detection. Journal of Chromatography B: Biomedical Sciences and Applications 1998; 734(2): 229-246.

[8] Leucht S, Corves C, Arbter D, Engel RR, Li C and Davis JM. Secondgeneration versus first- generation antipsychotic drugs for schizophrenia: a meta-analysis. Lancet 2008; 373(9657): 31-41.

[9] Lieberman JA, Stroup TS, McEvoy JP, Swartz MS, Rosenheck RA, Perkins DO, Keefe RS, Davis SM, Davis CE, Lebowitz BD, Severe J and Hsiao JK. Clinical Antipsychotic Trials of Intervention Effectiveness (CATIE). Effective- ness of antipsychotic drugs in patients with chronic schizophrenia. The New England Journal of Medicine 2006; 353(12): 1209-1223.

[10] Liu Y, Zhang MQ, Jia JY, Liu YM, Liu GY, Li SJ, Wang W, Weng LP and $\mathrm{Yu} \mathrm{C}$. Bioequivalence and Pharmacokinetic Evaluation of Two Formulations of Risperidone $2 \mathrm{mg}$ : an open-label, single- dose, fasting, randomized- sequence, two-way crossover study in healthy male Chinese volunteers. Drugs in $R \& D$ 2014; 13(1): 29-36.

[11] Mandrioli R, Mercolini L, Cesta R, Fanali S, Amore $\mathrm{M}$ and Raggi MA. Analysis of the second-generation antidepressant venlafaxine and its main active metabolite $O$ desmethylvenlafaxine in human plasma by HPLC with spectrofluorimetric detection. Journal of Chromatography B: Analytical Technologies in the Biochemical and Life Sciences 2008; 856(1-2): 88-94

[12] Meyer MJ. Goodman \& Gilman's The Pharmacological Basis of Therapeutics: Pharmacotherapy of Psychosis and Mania, 12th edn, Brunton L, Chabner B and Knollman B (eds.). McGraw-Hill: New York, 2012; 417-455.

[13] Schatz DS and Saria A. Simultaneous determination of paroxetine, risperidone and 9-hydroxyrisperidone in human plasma by highperformance liquid chromatography with coulometric detection. Pharmacology 2001; 60(1): 51-56.

[14] Sheehan JJ, Sliwa JK, Amatniek JC, Grinspan A and Canuso CM. Atypical antipsychotic metabolism and excretion. Current Drug Metabolism 2011; 11(6): 516-525. 
[15] Shen YL, Wu HL, Ko WK and Wu SM. Simultaneous determination of cloza- pine, clozapine N - oxide, N desmethylclozapine, risperidone, and 9-hydroxyrisperidone in plasma by high performance liquid chromatography with ultraviolet detection. Analytica Chimica Acta 2001; 460: 201-208.

[16] Suckow RF, Zhang MF and Cooper TB. Sensitive and selective liquidchromatographic assay of fluoxetine and norfluoxetine in plasma with fluorescence detection after precolumn derivatization. Clinical Chemis- try 1993; 38(9): 1756-1761.

[17] Urinovska R, Brozmanova H, Sistik P, Silhan P, Kacirova I, Lemr K and Grundmann M. Liquid chromatography-tandem mass spectrometry method for determination of five antidepressants and four atypical an- tipsychotics and their main metabolites in human serum. Journal of Chromatography B: Analytical Technologies in the Biochemical and Life Sciences 2011; 907: 101-107.

[18] US DHHS, FDA and CDER. Guidance for Industry: Bioanalytical Method Validation. US Department of Health and Human Services, Food and Drug Administration, Center for Drug Evaluation and Research and Center for Veterinary Medicine: Rockville, MD, 2002.

[19] Zhang G, Terry AV Jr and Bartlett MG. Simultaneous determination of five antipsychotic drugs in rat plasma by high performance liquid chroma- tography with ultraviolet detection. Journal of Chromatography B: Ana- lytical Technologies in the Biochemical and Life Sciences 2006; 856(1-2): 20-28. 